\title{
MULTIPHYSICS NUMERICAL SIMULATIONOF ORANGE JUICE POUCH THERMAL TREATMENT
}

\author{
Saif T. Manji \\ Chemical Engineering Department, Faculty of Engineering, Koya University Kurdistan Region, Iraq
}

\begin{abstract}
Thermal treatment of fresh juice is vital to neutralize harmful bacteria that would pose threat to human health. This work is dedicated to simulate the thermal inactivation of Salmonella enteritidis and e coli and its impact on the degradation of four nutrition compounds: $\beta$-carotene, $\beta$-cryptozanthin, zeinoxanthin, and ascorbic acid that give fresh fruit juice its benefits. The simulation is conducted in a multiphysics environment that accounts for the fluid motion induced by convection heat transfer and species transport with chemical reaction. In this study, a $6 \mathrm{~cm} \times 4 \mathrm{~cm} \times 11 \mathrm{~cm}$ orange juice pouch subjected to121oC saturated steam in a steam retort had been simulated to find the optimum time for pathogen inactivation and nutrients retention. It was seen that 4 minutes would reduce the number of viable populations of salmonella and e coli to 2.82 and $3.46 \log C F U / m l$ respectively, permitted values that pose no threat to human health. And maintain retention values of 92.791, 87.653, 90.048, and 98.984\% retention for $\beta$-carotene, $\beta$-cryptozanthin, zeinoxanthin, and ascorbic acid respectively.
\end{abstract}

Keywords: Thermal Treatment, Pasteurization, Orange Juice, Computational Fluid Dynamics, Multiphysics Simulation

\section{INTRODUCTION}

Fruit juice is among the most demanded food products especially as the awareness of its benefits of being rich of vitamins, e.g. vitamin $\mathrm{C}$, its high potassium content and helps in preventing from many diseases such as heart diseases, cancer, and diabetes[1]. But despite its importance, fresh juice have shown to be of great risk to human health since it contain pathogens such as Escherichia coli (ecoli) and salmonella[2, 3]. Therefore treatment methods were developed to reduce these pathogen populations to lower their risks on human health. For salmonella, the reported infectious dose varies $10^{3}$ to $10^{10}$ bacilli depending on the serotype while e coli has an infectious dose varying between $10^{6}$ and $2.3 \times 10^{10}$ bacilli[4, 5].One of the earliest methods of food preservation is thermal treatment using steam retorts, which proves until present time to be efficient and economic[6]. In steam retorts, food packages, in general, are exposed to steam for a controlled period of time in order to reduce the pathogen population to permitted levels that pose no threat to human health.

Thermal treatment was targeted by numerous researches that sought to investigate the time required for thermal treatment and impact on quality retention. From these prominent studies, the followings are mentioned: Abdul Ghani et al[7] simulated the thermal treatment of cylindrical can by using saturated steam at $121^{\circ} \mathrm{C}$ and extending the model by including natural convection and bacteria deactivation to predict the slowest and its effect on the distribution of bacteria concentration. Abdul Ghani et al[8] studied the sterilization of a 3D model pouch containing carrot-orange soup and found the transient temperature, velocity profiles and the shape of the slowest heating zone. Manso et al[9] analyzed the thermal degradation of ascorbic acid and
Dehydroascorbic acid in orange juice, $\mathrm{pH}$ and browning under the conditions from 20 to $45{ }^{\circ} \mathrm{C}$ temperature range. Mayer et al[10] studied the impact of thermal treatment on carotenoids, vitamin $\mathrm{C}$, and hesperidin of citrus juice between 50 and $100^{\circ} \mathrm{C}$. Tiwari et al[11] made a comparison between thermal pasteurization and sonication of orange juice and evaluated the Ascorbic acid degradation kinetics and predicted the shelf life for both methods. Augusto and Cristianini[12] performed a CFD study on thermal processing of a brick shaped packages with the consideration of its orientation on the process lethality. The simulation involved liquid water to represent the food material and Clostridium botulinum as pathogen. Dhayal et al[13] developed a CFD model to investigate the sterilization of canned milk at $121{ }^{\circ} \mathrm{C}$ for different can orientations and its effect on slow heating zone.

This study aims to simulate the thermal sterilization process of a $12.2^{\circ}$ Brix orange juice in an unprecedented manner that takes into consideration the prediction of the death curve of Escherichia coli (e coli) and Salmonella enteritidis, the commonly expected pathogens in citrus juices that are capable of surviving acidity[2,3], the prediction of the degradation of $\beta$ - carotene, $\beta$ - cryptozanthin, zeinoxanthin, and ascorbic acid (Vitamin $C$ ) and the heat transfer effects in a brick-shaped orange juice pouch. The simulation was performed in a multiphysics environment that couples all above different physics together in order to predict the transient temperature, velocity, nutrition degradation and population decline and have a deep in understanding of the impact of the thermal sterilization on the valuable nutrients that given the orange juice its benefits. For this purpose a three-dimensional pouch model has been prepared that accounts for natural convection inner circulation effects. 


\section{MATERIALS AND METHODS}

The present study was based on collection previous works[4, $6,14]$. Each treated a certain aspect of the thermal treatment process. Here, attempt was made to bring these findings into a single work and make use of the multiphysics modeling capabilities of COMSOL Multiphysics ${ }^{\circledR}$ to solve the problem. The first part is to collect the required physical to model the fluid dynamics, heat transfer, and mass transport correctly. And in the second part, the governing equations for the process are outlined.

\subsection{Physical Properties}

In order to have accurate predictions of the thermal treatment, physical properties have to be evaluated as a function of temperature as done with the density and viscosity. All except for heat capacity and thermal conductivity were expressed as temperature dependent as shown in Table 1.

Table -1: Physical properties of orange juice evaluated at $12.2^{\circ}$ Brix orange juice

\begin{tabular}{|l|l|l|}
\hline & Expression/value & Ref. \\
\hline Density, kg/m ${ }^{3}$ & $1068.088-0.3289 \mathrm{~T}$ & {$[15]$} \\
\hline Viscosity, Pa.s & $7 \times 10^{7} \mathrm{~T}^{2}-3 \times 10^{5} \mathrm{~T}+0.0012$ & {$[16]$} \\
\hline $\begin{array}{l}\text { Heat capacity, } \\
\mathrm{kJ} / \mathrm{kg} . \mathrm{K}\end{array}$ & 3.73 & {$[17]$} \\
\hline $\begin{array}{l}\text { Thermal } \\
\text { conductivity, } \\
\text { W/m.K }\end{array}$ & 0.32 & {$[17]$} \\
\hline
\end{tabular}

\subsection{Mathematical Model}

Fluid motion was assumed to be Newtonian, a satisfactory assumption for low sugar content fruit juice [15] Thus, the governing equations are:

\section{Mass balance}

$\rho \nabla \cdot(\mathbf{u})=0$

\section{Momentum balance}

$\rho \frac{\partial \mathbf{u}}{\partial t}+\rho(\mathbf{u} \cdot \nabla)=\nabla \cdot\left[-p \mathbf{I}+\mu\left(\nabla \mathbf{u}+(\nabla \mathbf{u})^{\mathrm{T}}\right)\right]+\mathbf{F}$

where $\rho$ is the juice density in $\mathrm{kg} / \mathrm{m}^{3}, \mathbf{u}$ is the velocity vector, $\mathrm{p}$ is the pressure in $\mathrm{Pa}, \mathbf{F}$ is the volume force vector in $\mathrm{N} / \mathrm{m}^{3}$.

Energy balance

$$
\rho C_{p}\left(\frac{\partial T}{\partial t}+\mathbf{u} \cdot \nabla T\right)+\nabla \cdot \mathbf{q}=Q
$$

$$
\mathbf{q}=k \nabla T
$$

Where $C_{p}$ is the heat capacity in $\mathrm{kJ} / \mathrm{kg} . \mathrm{K}, \mathbf{q}$ is the heat flux in $\mathrm{W} / \mathrm{m}^{2}$ and $\mathrm{k}$ is the thermal conductivity in $\mathrm{W} / \mathrm{m} . \mathrm{K}$.

\section{Transport equation}

The nutrients motion was assumed to follow Fick's law and the transport of diluted species interface was selected to model this scenario. $\frac{\partial c_{i}}{\partial t}+\nabla \cdot\left(-D_{i} \nabla c_{i}\right)+\mathbf{u} \cdot \nabla \cdot c_{i}=R_{i}$

$\mathbf{N}_{i}=-D_{i} \nabla c_{i}+\mathbf{u} c_{i}$

where $\mathrm{c}$ is the concentration in $\mathrm{mol} / \mathrm{m}^{3}, \mathrm{R}$ is the reaction rate in $\mathrm{mol} / \mathrm{m}^{3} . \mathrm{s}, \mathbf{N}$ is the molar flux in $\mathrm{mol} / \mathrm{m}^{2}$.s.

The diffusion coefficients of the nutrients are found from Wilke - Chang equation[18]

$$
\mathrm{D}=1.173 \times 10^{-16}\left(\varphi \mathrm{M}_{\mathrm{B}}\right)^{1 / 2} \frac{\mathrm{T}}{\mu \mathrm{V}_{\mathrm{A}}^{0.6}}
$$

where $\mathrm{D}$ is the diffusion coefficient in $\mathrm{m}^{2} /, \phi$ is the association coefficient, $M_{B}$ is the molecular weight of the liquid, $\mathrm{T}$ is the temperature in $\mathrm{K}$ except for Table 1 where it is in degree Celsius, $\mu$ is the viscosity in Pa.s and $V_{A}$ is the molar volume of solute.

The bacteria diffusion coefficients is evaluated from Stokes - Einstein's equation[7]

$\mathrm{D}=\frac{\mathrm{kT}}{6 \pi \mu \mathrm{a}}$

\section{Chemical Reactions}

\section{Nutrients Degradation}

The degradation of four nutrients is considered in this study ( $\beta$-carotene, $\beta$-cryptozanthin, zeinoxanthin, and ascorbic acid) and all the reactions were assumed to follow first order mechanism [10]

$\frac{\mathrm{dc}}{\mathrm{dt}}=\mathrm{kc}$

$\mathrm{k}=\mathrm{k}_{\infty} \mathrm{e}^{-\mathrm{E} / \mathrm{RT}}$

where $\mathrm{k}$ is the reaction rate in $1 / \mathrm{s}, \mathrm{k}_{\infty}$ is the frequency factor in $1 / \mathrm{s}$. $\mathrm{E}$ is the activation energy in $\mathrm{kJ} / \mathrm{mol}$, and $\mathrm{R}$ is the ideal gas constant.

Table -2: Kinetic parameters for the degradation reactions of nutrients [10]

\begin{tabular}{|l|l|l|}
\hline & $\operatorname{Ln~}_{\infty}\left[\mathrm{k}_{\infty}, 1 / \mathrm{s}\right]$ & $\mathrm{E}[\mathrm{kJ} / \mathrm{mol}]$ \\
\hline$\beta$-carotene & 27.415 & 110.0 \\
\hline$\beta$-cryptozanthin & 42.410 & 156.0 \\
\hline Zeinoxanthin & 31.519 & 122.8 \\
\hline Ascorbic Acid & 1.81 & 35.9 \\
\hline
\end{tabular}

\section{Pathogen Survival Curve}

The two pathogens e coli and salmonella are assumed to be first order [14].

TABLE 3: Kinetic parameters for the survival curve [14]

\begin{tabular}{|l|l|l|}
\hline & Ln $\mathrm{k}_{\infty}\left[\mathrm{k}_{\infty}, 1 / \mathrm{s}\right]$ & $\mathrm{E}[\mathrm{kJ} / \mathrm{mol}]$ \\
\hline Salmonella & 80.24 & 241.3 \\
\hline e coli & 69.68 & 214.5 \\
\hline
\end{tabular}

The number of viable organisms as a function of time for salmonella and e coli:

$$
\frac{\mathrm{dN}}{\mathrm{dt}}=-\mathrm{k} \mathrm{N}
$$


Boundary conditions and assumptions

The following boundary conditions are assumed for the present study:

1. The simulated pouch has the dimensions $6 \mathrm{~cm} \times 4 \mathrm{~cm} \times$ $11 \mathrm{~cm}$.

2. At the walls, no material is transfer from or to the pouch and the no-slip boundary condition was assumed.

3. The pouch is assumed to be surrounded by steam at $121^{\circ} \mathrm{C}$ and has a heat transfer coefficient of 3000 $\mathrm{W} / \mathrm{m}^{2} . \mathrm{K}$.

4. Heat is transferred from steam to pouch exterior walls by convection and within the package by conduction.

5. The package was assumed to be made of thin layers polypropylene, aluminium and polyester [8].

6. The initiall temperature $\left(25^{\circ} \mathrm{C}\right)$ and concentrations are assumed to be uniform throughout the pouch.

7. The orange juice sugar content is taken to be $12.2^{\circ}$ Brix.

8. The initial populations of Salmonella and e coli are 8.4 $\log \mathrm{CFU} / \mathrm{ml}$ and $8.09 \log \mathrm{CFU} / \mathrm{ml}[19]$.

\subsection{Solution Methodology}

The governing equations were solved using COMSOL Multiphysics $®$ in a sequential manner similar to[20]. Firstly, a 3D geometry of the pouch was prepared. Secondly, Laminar Flow interface was selected and the flow boundary conditions were defined to solve the model using time dependent study. Thirdly, Heat Transfer in Fluids interface was added to account for the natural convection and the exterior boundary conditions and the resulting model is solved using a new time dependent study by taking the results of the first study, and finally, Chemistry and Diffusion of Diluted Speciesinterfaces were added to model the reactions and nutrients and bacteria transport and solved the model by a third study that sets the initial expressions to the values obtained for the solution of the first two studies.

\subsection{Equations Discretization And Mesh}

The Navier-Stokes equations, energy balance, and transport equations were discretized using $2^{\text {nd }}$ order derivative for the velocity, temperature, and concentrations and $1^{\text {st }}$ order derivative for the pressure forward schemes.

The mesh used consists of tetrahedral for the bulk the pouch sizing between 0.4 and $0.14 \mathrm{~cm}$ and the boundaries were meshed using triangular mesh of element size from 0.04 to $0.2 \mathrm{~cm}$. to smooth the profiles two boundary layers were added to each surface.

\section{RESULTS AND DISCUSSION}

Upon running the simulation according to the solution procedure described in section 2.3 and the prescribed boundary conditions and assumptions to predict the transient behavior was obtained as shown in Figs 1-9. Figure 1 shows that the juice is flowing upwards at the boundaries and downwards at the core of the pouch. Figure 2 shows the velocity field for time intervals stepping 1 minute taken at mid-planes within the pouch to reveal the bulk behavior.
The planes were expressed as front and side planes. For the first 2 minutes, it is seen the side velocity field circulations exceed the front field and for both cases the velocity magnitude is higher at the beginning and declining as time proceeds.

The temperature distribution in Fig. 3 shows a temperature rise from top of the pouch and gradually crawls downwards as time proceeds as the hotter juice flows upwards near the walls and forms a hot region at the top due to its low density. This temperature increase gradually causes the liquid velocity to drop in the upper part of the pouch as the temperature tends to be uniform. The slow heating zone was seen to be formed at the bottom of the pouch where the relatively heavier fluid is kept circulated to. At the end of treatment (after 2 minutes) the lowest predicted temperature is $70.1^{\circ} \mathrm{C}$.

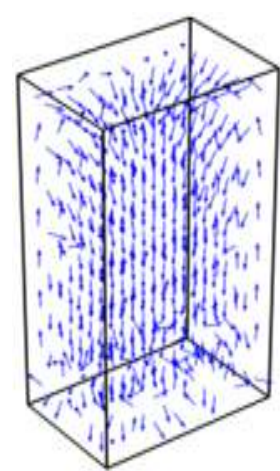

Fig - 1: 3D representation of the velocity field of orange juice after 1 minute of thermal treatment
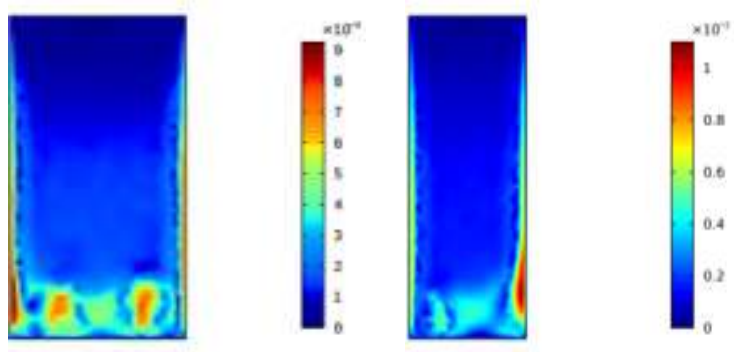

Front plane

Side plane

$1 \mathrm{~min}$
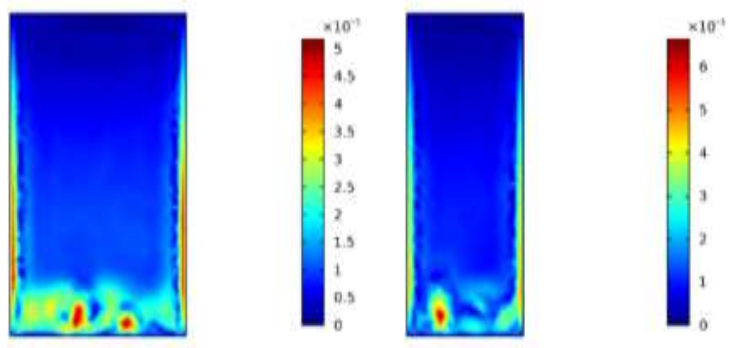

Front plane

2 min

Side plane

Fig -2: velocity fieldof the orange juice obtained for different time intervals at mid planes in the pouch 

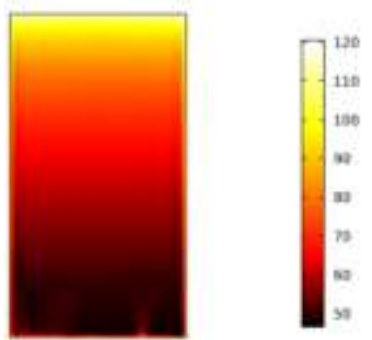

Front plane

$1 \mathrm{~min}$

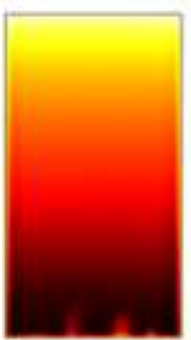

Front plane 2 min

Fig - 3: Temperature distribution obtained for different time intervals at mid planes in the pouch

The populations of salmonella and e coli shown in Figs. 4-5 were plotted as normalized numbers vs. time rather than the conventional decimal reduction time plot. Both pathogen profiles display a pattern that is strongly influenced by the velocity field and temperature distribution. The viable pathogens near the pouch walls are diminishing while in the slow heating zone it can be seen that number of viable pathogen remains at its highest values. Figures5-6 show the average normalized populations reach $2.6 \times 10^{-6}$ and $2.3 \times 10^{-5}$ after 3.5 and 4 minutes for salmonella and e coli respectively (not visible Figs 5-6). These normalized populations are equivalent to 2.82 and $3.46 \log \mathrm{CFU} / \mathrm{ml}$ for salmonella and e coli respectively which can considered to be acceptable[21].

The salmonella was seen to inactivate faster than the e coli because of the faster reaction rate that would cause the salmonella viable organism to deplete it faster than e coli.

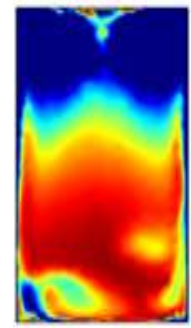

Front plane $0.3 \mathrm{~min}$
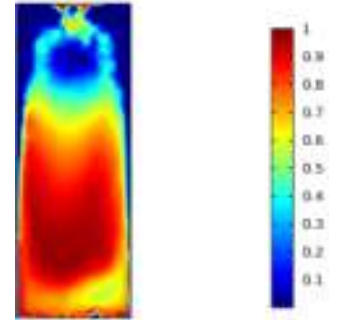

Side plane

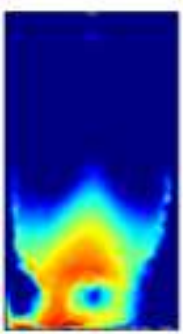

Front plane $0.5 \mathrm{~min}$

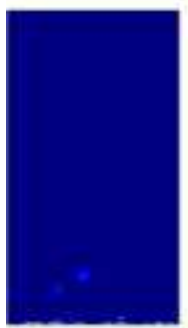

Front plane $0.8 \mathrm{~min}$

Fig - 4: Normalized viable population of Salmonella for different time intervals at mid planes in the pouch

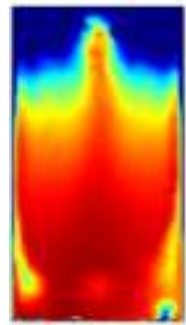

Front plane $0.5 \mathrm{~min}$

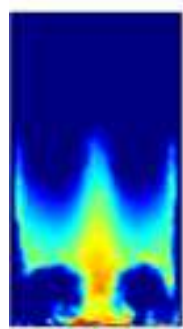

Front plane $1 \mathrm{~min}$

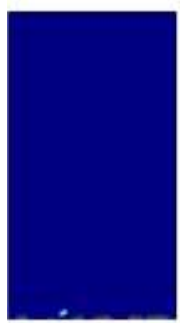

Front plane $2 \mathrm{~min}$
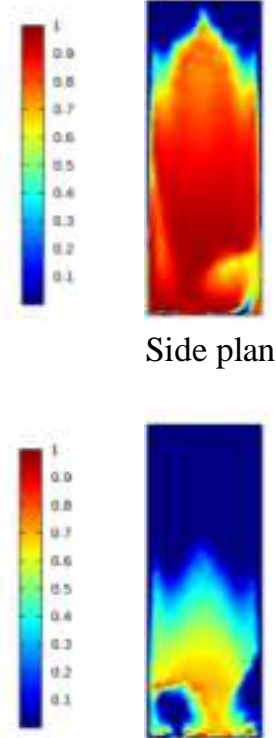

Side plane

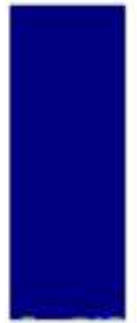

Side plane

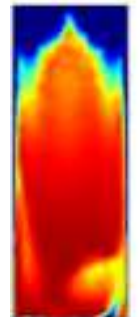

Side plane

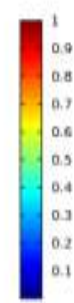

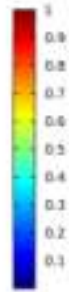

Fig - 5: Normalized viable population of e coli for different time intervals at mid planes in the pouch 


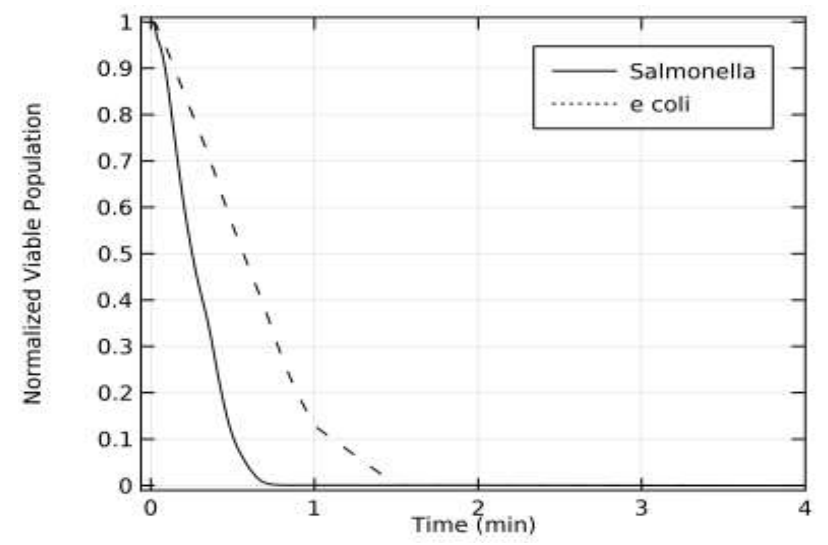

Fig -6: Normalized Average pathogen population evaluated for the whole pouch at different time intervals

The concentration distribution of the nutrients will be visualized through a plot of the average value of the concentrations versus time (Fig. 7) by making use of the average coupling. After 4 minutes it is predicted to achieve $92.791,87.653,90.048$, and $98.984 \%$ retention for $\beta$ carotene, $\beta$ - cryptozanthin, Zeinoxanthin, and Ascorbic Acid respectively.

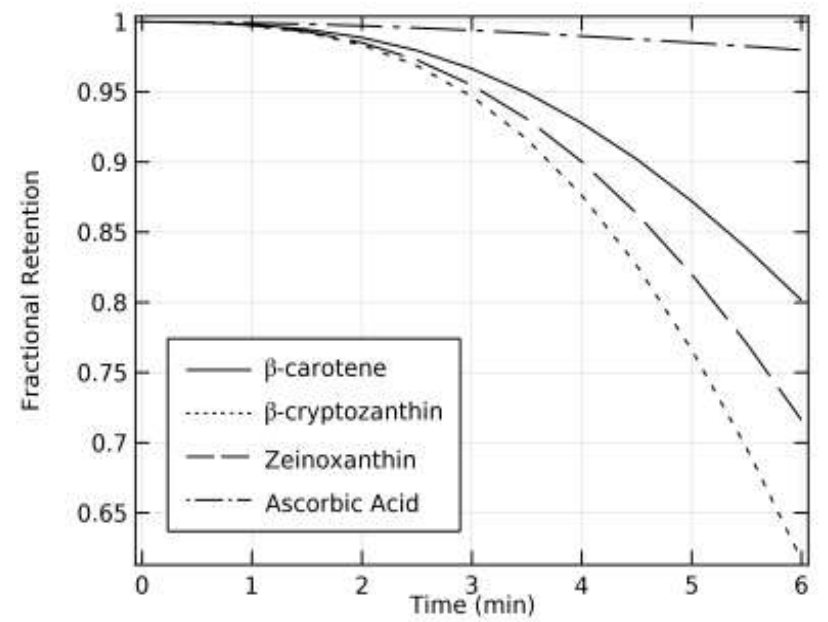

Fig -7: Normalized Average nutrients concentrations evaluated for the whole pouch at different time intervals

\section{Average Heat Transfer Coefficient}

The heat flux from the steam surrounding the pouch $(\mathrm{h}=$ $3000 \mathrm{~W} / \mathrm{m}^{2} . \mathrm{K}$ ) is evaluated at the six boundaries and then locally averaged for each time interval. Both wall $\bar{T}_{w}$ and bulk Ttemperatures around the boundaries are averaged and the heat transfer coefficient of the orange juice is calculated from:

$$
\overline{\mathrm{q}_{\mathrm{w}}}=\overline{\mathrm{h}}\left(\overline{\mathrm{T}}_{\mathrm{w}}-\overline{\mathrm{T}}\right)
$$

where $\overline{q_{w}}$ is the average heat flux in $\mathrm{W} / \mathrm{m}^{2}$ transferred through the boundaries from the steam, $\bar{T}_{\underline{w}}$ is the average inner wall temperature of the pouch and $\bar{T}$ is the average bulk temperature.

The average heat flux shown in Fig. 8 is declining with time as the pouch's average temperature tends to reach the surroundings temperature.The local heat transfer coefficient which was seen in[6] to be nearly constant is omitted from this study. Therefore, only the average heat transfer coefficient was adopted in this research as shown in Fig. 9.

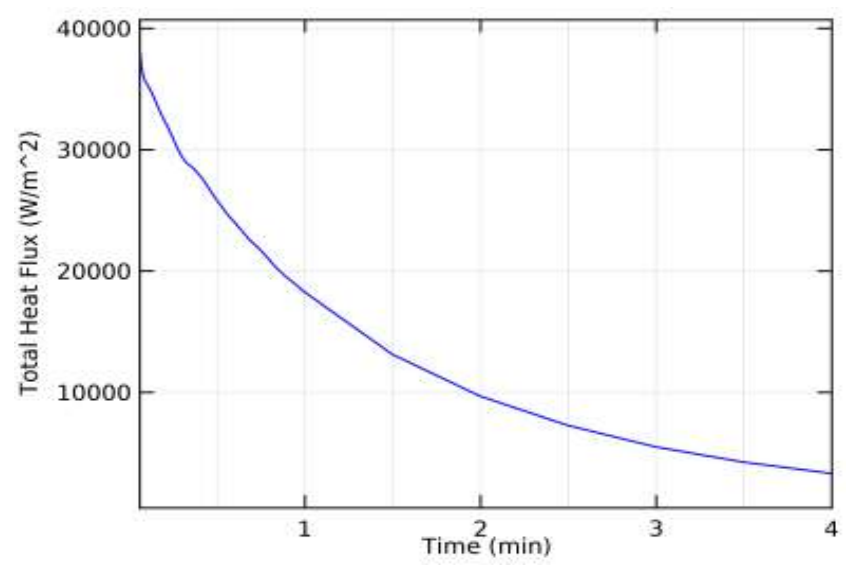

Fig -8: Average heat flux through the boundaries of the as a function of time

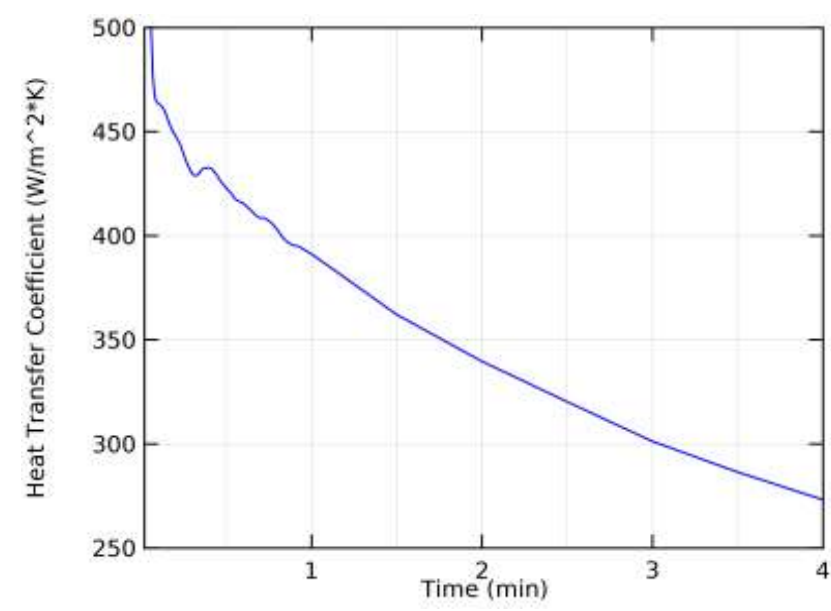

Fig -9: Average heat transfer coefficient as function of time. Evaluated from equation (12)

\section{CONCLUSIONS}

From the observed results it is clear that multiphysics CFD simulation is of great importance since it helps to predict accurately the outcome of the thermal inactivation of orange juice pouch that helps neutralizing the harmful salmonella and e coli by predicting the time required to for this process. For such process time underprediction would lead incomplete pasteurization and consequently endanger human health whereas overprediction would cause further degradation of the valuable nutrients of the orange juice.

From this study, it was observed that the pasteurization time using $121^{\circ} \mathrm{C}$ saturated steam for treating a $6 \mathrm{~cm} \times 4 \mathrm{~cm} \times 11 \mathrm{~cm}$ orange juice pouch made of thin layers of polypropylene, aluminium and polyester is about 4 mimutes. This time will reduce the the number of viable poupulations of salmonella and e colito 2.82 and $3.46 \log \mathrm{CFU} / \mathrm{ml}$ for respectively, a permitted values that pose no threat to human health. And maintain retention values of $92.791,87.653,90.048$, and $98.984 \%$ retention for $\beta$-carotene, $\beta$-cryptozanthin, zeinoxanthin, and ascorbic acid respectively. 


\section{REFERENCES}

[1]. K. Aneja, R. Dhiman, N. Aggarwal, V. Kumar and M. Kaur, "Microbes Associated with Freshly Prepared Juices of Citrus and Carrots," International Journal of Food Science, vol. 2014, pp. 1-7, 2014.

[2]. Castillo, A. Villarruel-López, V. Navarro-Hidalgo, N. Martínez-González and M. Torres-Vitela, "Salmonella and Shigella in freshly squeezed orange juice, fresh oranges, and wiping cloths collected from public markets and street booths in Guadalajara, Mexico: incidence and comparison of analytical routes," Journal of Food Protection, vol. 69, no. 11, pp. 2595-9, 2006.

[3]. O. Oyarzábal, M. Nogueira and D. Gombas, "Survival of Escherichia coli O157:H7, Listeria monocytogenes, and Salmonella in juice concentrates," Journal of Food Protection, vol. 66, no. 9, pp. 1595-8, 2003.

[4]. M. Bronze and R. Greenfield, Biodefence Principles and Pathogenshorizon bioscience, Horizon Bioscience, 2005

[5]. K. M.H. and U. Babu, "Infective dose of foodborne pathogens in volunteers: a review," Journal of Food Safety, vol. 21, no. 1, pp. 49-68, 2001

[6]. Kannan and P. C. Gourisankar Sandaka, "Heat transfer analysis of canned food sterilization in a still retort," Journal of Food Engineering, vol. 88, pp. 213-228, 2008.

[7]. Abdul Ghani, M. Farid, X. Chen and P. Richards, "An investigation of deactivation of bacteria in a canned liquid food," Journal of Food Engineering, vol. 42, pp. 207-214, 1999

[8]. Abdul Ghani, M. Farid and P. Chen, "Thermal sterilization of canned food in a 3-D pouch using computational fluid dynamics," Journal of Food Engineering, vol. 48, pp. 147-156, 2001

[9]. M. Manso, F. Fernanda, J. Oliveira and J. Frias, "Modelling ascorbic acid thermal degradationand browning in orange juice under aerobic conditions," International Journal of Food Science and Technology, vol. 36, pp. 303-312, 2001

[10]. Dhuigue-Mayer, M. Tbatou, M. Carail, C. Caris-Verat, M. Dornier and M. Amiot, "Thermal Degradation of Antioxidant Micronutrients in Citrus Juice: Kinetics and Newly Formed Compounds," Journal of Agriculture and Food Chemistry, vol. 55, pp. 42094216, 2007.

[11]. B. Tiwari, C. O’ Donnell, K. Muthukumarappan and P. Cullen, "Ascorbic acid degradation kinetics of sonicated orange juice during storage and," LWT Food Science and Technology, vol. 42, pp. 700-704, 2009

[12]. P. Augusto, T. Pinheiro and M. Cristianini, "Using Computational Fluid-Dynamics (CFD) for the evaluationof beer pasteurization: effect of orientation of cans," Ciência e Tecnologia de Alimentos, vol. 30, no. 4, pp. 980-986, 2010.

[13]. P. Dhayal, N. Chhanwal and C. Anandharamakrishnan, "Heat Transfer Analysis of Sterilization of Canned Milk," Journal of Food Science and Engineering, vol. 3, pp. 571-583, 2013
[14]. Heldman, Food Preservation Process Design, Elsevier Inc., 2011.

[15]. R. Ibarz, V. Falguera, A. Garvin, S. Garza, J. Pagan and A. Ibarz, "FLOW BEHAVIOR OF CLARIFIED ORANGE JUICE," Journal of Texture Studies, vol. 40, pp. 445-456, 2009

[16]. Hernandez, C. Chen, J. Johnson and R. Carter, "Viscosity Changes in Orange Juice After Ultrafiltration and Evaporation," Joumal of Food Engineering, vol. 25, pp. 387-396, 1995

[17]. M. Rahman, Food Properties Handbook, Taylor \& Francis Group, LLC, 2009.

[18]. Wilke and P. Chang, "Correlation of diffusion coefficients in dilute solutions," AIChE Journal, vol. 1, no. 2, p. 264-270, 1955

[19]. Teo, S. Ravishankar and C. Sizer, "Effect of lowtemperature, high-pressure treatment on the survival of Escherichia coli O157:H7 and Salmonella in unpasteurized fruit juices," Journal of Food Protection, vol. 64, no. 8, pp. 1122-7, 2001

[20]. COMSOL, "Thermal Decomposition," COMSOL Inc., 2015.

[21]. "Microbiological quality guide for ready-to-eat foods," The NSW Food Authority, 2009 